significant improvement was $64 \%$ for $\mathrm{FEV}_{1}$ $\left(12 \%\right.$ improvement in $\left.\mathrm{FEV}_{1}\right), 31 \%$ for exercise capacity ( 6 min walk test of more than $54 \mathrm{~m}$ ) and $71 \%$ for SGRQ (reduction by four points). However, the degree of improvement needs to be interpreted with caution as small open-label cohort studies tend to consistently demonstrate a greater degree of benefits than are ultimately observed in large-scale randomised trials. This effect may be exaggerated as the authors have only looked at a subgroup (28 patients who had derivable information on fissure status on CT scans) rather than the whole cohort of 54 patients treated.

This study has not reported on the safety aspects but a previous study of 25 patients suggests an early transient systemic inflammatory response with fevers, flu-like symptoms and chest discomfort. ${ }^{12}$ There were exacerbations of chronic obstructive pulmonary disease (COPD) in eight patients requiring hospitalisation and one needed treatment in an intensive care unit. The event rate may seem high but should be considered in the context of this population of patients who have severe disease, frequent exacerbations and limited treatment options. However, treatment with the polymeric foam sealant is irreversible. It remains in situ in the lung and induces permanent sclerosis. Longer-term effects remain unclear and it should be used with caution in patients with Global Initiative for Chronic Obstructive Lung Disease (GOLD) stage III disease.

Bronchoscopic lung volume reduction should be considered in patients with severe emphysema with evidence of hyperinflation (residual volume $>180 \%$ predicted) who are symptomatic despite maximal medical therapy. Endobronchial valves which are easily removed should be considered initially in patients who have an intact fissure on CT scans or evidence of low collateral ventilation. Patients who have significant collateral ventilation may need to be considered for alternative treatments such as the polymeric foam sealant.

Contributors This editorial was jointly written by PS and DG.

Competing interests PS has been involved in a number of clinical trials on bronchoscopic lung volume reduction and the host centres (Royal Brompton Hospital and the Chelsea \& Westminster Hospital) have been reimbursed for clinical trial expenses. There are no competing interests with respect to the emphysematous lung sealant (AeriSeal囚). DM has no competing interests.

Provenance and peer review Not commissioned; internally peer reviewed.

Published Online First 28 February 2012

Thorax 2012;67:285-286.

doi:10.1136/thoraxjnl-2012-201648

\section{REFERENCES}

1. Sciurba FC, Ernst A, Herth FJ, et al; VENT Study Research Group. A randomized study of endobronchial valves for advanced emphysema. N Engl J Med 2010;363:1233-44.

2. Herth FJ, Noppen M, Valipour A, et al. Efficacy predictors of lung volume reduction with Zephyr valves in a European cohort. Eur Respir J Published Online First 26 Jan 2012. doi:10.1183/ 09031936.00161611

3. Ninane V, Geltner C, Bezzi M, et al. Multicentre European study for the treatment of advanced emphysema with bronchial valves. Eur Respir J. In press.

4. Hopkinson NS, Shah PL, Polkey MI. Endobronchial valves for emphysema. N Engl J Med 2011;364:381-2.

5. Hopkinson NS, Kemp SV, Toma TP, et al. Atelectasis and survival after bronchoscopic lung volume reduction for COPD. Eur Respir $J$ 2011;37:1346-51.

6. Cetti EJ, Moore AJ, Geddes DM. Collateral ventilation. Thorax 2006:61:371-3.

7. Macklem PT. Collateral ventilation. N Engl J Med 1978;298:49-50.

8. Moore AJ, Cetti E, Haj-Yahia S, et al. Unilateral extrapulmonary airway bypass in advanced emphysema. Ann Thorac Surg 2010;89:899-906.

9. Shah PL, Slebos DJ, Cardoso PF, et al; EASE Trial Study Group. Bronchoscopic lung-volume reduction with Exhale airway stents for emphysema (EASE trial): randomised, sham-controlled, multicentre trial. Lancet 2011;378:997-1005.

10. Ingenito EP, Reilly JJ, Mentzer SJ, et al. Bronchoscopic volume reduction: a safe and effective alternative to surgical therapy for emphysema. Am $J$ Respir Crit Care Med 2001;164:295-301.

11. Magnussen H, Kramer RM, Kirsten AM, et al. Effect of fissure integrity on lung volume reduction using a polymer sealant in advanced emphysema. Thorax 2012:67:302-8

12. Herth FJ, Gompelmann D, Stanzel F, et al. Treatmen of advanced emphysema with emphysematous lung sealant (AeriSeal®). Respiration 2011;82:36-45.

\title{
MDR, XDR, TDR tuberculosis: ominous progression
}

\section{Zarir F Udwadia}

\begin{abstract}
Any man's death diminishes me because I am involved in mankind, and therefore never send to know for whom the bell tolls; it tolls for thee... (John Donne, Meditation XV11)

The growing TB epidemic is no longer an emergency only for those who care about health, but also for those who care about justice. (PD O Davies)
\end{abstract}

For 2 weeks in January, India coughed and the rest of the world paid attention. Drugresistant tuberculosis (TB), languishing from a decade of neglect by the Indian

Correspondence to Zarir F Udwadia, Hinduja Hospital and Research Center, Mumbai 400020, India; zfu@hindujahospital.com
Revised National Tuberculosis Control Program (RNTCP), was headline news in every Indian newspaper and several international ones as well.

What captured local and international attention was a report documenting the isolation of the first cases of totally drug resistant TB (TDR-TB) from India. ${ }^{1}$ The Indian government's response, after initial denial, swung from the ridiculous to the sublime. The WHO response was far more measured and authoritative. Paul Nunn, coordinator of WHO's STOP TB department in Geneva, described the cases as "a wake up call for countries to accelerate provision of proper care, particularly for multi drug-resistant patients". Within a week WHO had a TDR link on its website with answers to frequently asked questions, was planning a new consensus definition of TDR-TB, and had planned an expert meeting to rethink strategy.

$\mathrm{TB}$ exists on an epic scale in India. It resolutely remains India's biggest public health problem. India bears a disproportionately large burden of the world's TB, one a developing country can ill afford, with an estimated economic loss of US $\$ 43$ billion and 100 million productive days lost annually directly due to this disease. The facts speak for themselves: India is the highest TB burden country in the world with 300 million Indians infected, accounting for $21 \%$ of the global incidence. $^{2}$ It is estimated that TB kills 300000 Indians annually: one death every 2 min, a grim statistic that has changed little over the decades. ${ }^{3}$

The situation is even worse when it comes to multidrug resistant TB (MDRTB). Here again India emerges a global hot spot with the latest WHO anti-TB drug 
resistance report estimating that India with its 110132 cases in 2006 represented $20 \%$ of the world's MDR-TB burden. ${ }^{4}$ These figures are a considerable underestimate because the majority of patients with MDR-TB are seen in the private sector and never notified.

While MDR-TB first emerged in the early 1990s, the first Indian cases of extensively drug-resistant (XDR)-TB were described from our centre in 2006, a few months after the initial Morbidity and Mortality Weekly Report. ${ }^{5}{ }^{6}$ But in just a few years the focus has switched again to TDR-TB. The first two cases of TDR-TB (coined XXDR-TB) were reported by Migliori in Italy in 2007. ${ }^{7}$ Then, Velayati reported a cohort of 15 patients with TDR-TB from Iran in 2009. ${ }^{8}$ There was no further mention of TDR-TB for 3 years till our publication of the first four Indian cases. Since then we have encountered a further eight cases. These 12 patients, sadly, hold a mirror to the way MDR-TB is mismanaged in India. The typical patient had failed both standard short course chemotherapy with 2HRZE/ $4 \mathrm{HR}$ (category 1), and then category 2 treatment, a single standardised retreatment regimen with 2HRZES/HRZE/ $5 \mathrm{HRE}$, in the public sector. They then turned, in desperation, to multiple private practitioners (PPs) whose inappropriate prescriptions only served to further amplify resistance till the microorganisms were finally resistant to all first-line (isoniazid, rifampicin, ethambutol, pyrazinamide, streptomycin) and second-line drugs (SLDs) tested by us at the Hinduja Hospital and Research Center, Mumbai (ofloxacin, moxifloxacin, kanamycin, amikacin, capreomycin, ethionamide, para-amino salicylic acid). The 12 patients (mean age 32 years, 6 men), had seen an average of four doctors, and received a mean of 9.33 drugs for an average duration of 26 months prior to being labelled TDR-TB by us.

What treatment options can we offer the damned? As Paul Farmer said: "Our mission must be to treat the sick, not just the sick who can pay. Our mission must be to treat $\mathrm{TB}$ regardless of resistance pattern." With the very limited treatment options available, we started each patient on a salvage regimen of four new drugs. In addition, aggressive surgery (pneumonectomy) was offered to two patients despite the bilateral nature of their disease. Three patients succumbed to their disease within a few months of being labelled TDR-TB.

TDR-TB is an iatrogenic disease that represents a failure of physicians, public and private, and a failure of public health. These patients have slipped through the cracks in India's TB control programme and it is informative to analyse where we have collectively failed them.

Let us turn first to the private sector. This sector in India, which manages more than half of all patients with $\mathrm{TB}$, is a continuing source of mismanagement of $\mathrm{TB}$ and operates largely outside the confines of the RNTCP. 9 It is highly disorganised with a lack of regulation in prescribing practice and the qualification of those prescribing TB drugs. Doctors of competing faiths, including general practitioners, homoeopaths, and Ayurveda specialists, 'prescribe' SLDs to patients with MDR-TB without compunction.

Our study from Mumbai in 2010 audited the MDR-TB prescribing practice of 106 PPs working in Dharavi, Asia's most populous slum (2.5 million people in $2 \mathrm{~km}^{2}$ ), and found only three prescriptions to be appropriate in that they contained a minimum of three new SLDs in the right doses and for the right duration. ${ }^{10}$ The majority of prescriptions were inappropriate and served to merely amplify resistance, with $70 \%$ of prescriptions only adding a single SLD (usually a fluoroquinolone). Thus poor prescribing practice by PPs is one of the key factors fuelling India's MDR-TB epidemic.

The public sector is equally to blame. While India's RNTCP, which embraced directly observed treatment short course (DOTS) in 1996, has been justly hailed as a global success story, it has equally spectacularly failed the huge and rising proportion of patients with MDR-TB it leaves in its wake. Patients whose condition fails to respond to DOTS category 1 treatment (estimated to number 0.2 million/year), instead of promptly having drug susceptibility testing (DST) and treatment based on their sensitivity profiles, are subjected to the suboptimal category 2 treatment regimen described above, which, illogically, adds a single and weak drug (streptomycin) to first-line drugs that have already failed, thus violating the basic tenet of 'never add a single drug to a failing regimen'. It serves to merely amplify resistance over a further 8 months, allowing drug-resistant TB to spread among crowded communities. DSTs, if and when they are finally asked for when category 2 treatment fails, as it often does, take a further 2 months to arrive. By this time 16 months have elapsed, during which time patients have disseminated resistant strains in crowded communities. Once MDR is finally diagnosed, the RNTCP again fails these patients, as it currently offers treatment with SLDs to $<1 \%$ of this vast pool of patients with chronic MDR-TB within the confines of a few DOTS-plus pilot projects. The vast majority, truly India's 'untouchables', are left to fend for themselves and desperately seek out a variety of PPs, exhausting finances, running up loans which devastate families, till MDR is further amplified to XDR and finally, and most grimly, to TDRTB.

Thus, decades of mismanagement of MDR-TB at government and private care levels have resulted in amplification of the level of resistance till we have finally ended up with a virtually untreatable strain.

\section{SOLUTIONS}

1. Laboratory capacity needs to be urgently increased. MDR, XDR and TDR-TB remain essentially microbiological diagnoses. In the 27 high-burden countries for MDR-TB, only $1 \%$ of cases received a DST in 2008. It is one of those sad TB paradoxes that India, which bears the lion's share of the world's TB burden, has only one of the 26 supranational reference laboratories (SRLN), while the majority are concentrated in the European Union and the USA, despite only $1 \%$ of the 9 million new TB cases in 2007 occurring in these regions.

2. DST should be offered early to all patients whose condition fails to respond to DOTS instead of subjecting them to category 2 treatment.

3. The WHO recommendation to make the GeneXpert test available needs to be incorporated across the country. It would make a huge difference to patients and transmission in society if physicians know they are dealing with MDR-TB with near $99 \%$ accuracy in $24 \mathrm{~h}$.

4. DOTS plus needs to move beyond the pilot study stage to broader implementation, despite the staggering additional finances involved. India's huge MDRTB population has waited too long for this basic injustice to be redressed.

5. Private public mix, too long a convenient WHO catchword, needs to become a reality. Indian patients fall into the chasm between the competing private and public systems and they need to be integrated.

6. New drugs are desperately needed. The two most promising candidates in the pipeline, TMC207 and OPC67863, are sadly, still several years away from clinical use. Till then, it is even more imperative that we do not squander available drugs with inappropriate prescriptions.

7. Finally, and perhaps most important, legislation needs to be passed to ensure 
that only designated specialists prescribe and treat patients with MDR-TB. This is the only way to ensure that inappropriate prescriptions do not hasten the slide into the hopeless inferno that is TDR-TB.

All this will take political will and funding, but, to quote Peter Small, "the fate of the world's poor is due to the inaction of those who are indifferent."

\section{Postscript}

On a more positive note, in response to the TDR-TB reports, the Union Health Ministry is planning a $400 \%$ hike in the TB budget in the country's 12th Five Year Plan and to reopen a 200-bed TB sanitarium in Mumbai that had been in a state of disuse as a dedicated MDR-TB treatment unit.
Contributors Dr Udwadia is the sole author

Competing interests None.

Provenance and peer review Commissioned; internally peer reviewed.

Thorax 2012;67:286-288.

doi:10.1136/thoraxjnl-2012-201663

\section{REFERENCES}

1. Udwadia ZF, Amale RA, Ajbani KK, et al. Totally drug-resistant tuberculosis in India. Clin Infect Dis 2012;54:579-81.

2. WHO Report 2010: Global Tuberculosis Control. Epidemiology, Strategy and Financing. Geneva: WHO, 2010.

3. Gopi PG, Subramani R, Santha T, et al. Estimation of burden of tuberculosis in India for the year 2000. Indian J Med Res 2005;122:243-8.

4. WHO IUATLD Global Project on Anti Tuberculosis Drug Resistance Surveillance (2002-2007), 4th Global Report. Geneva: World Health Organization, 2008
5. Jain S, Rodriguez C, Mehta C, et al. High prevalence of XDR-TB from a tertiary care hospital in India labstract A510]. American Thoracic Society 2007 International Conference. San Francisco, CA, USA, 2007.

6. Centers for Disease Control and Prevention (CDC). Emergence of Mycobacterium tuberculosis with extensive resistance to second line drugs worldwide, 2000-2004. MMWR Morb Mortal Wkly Rep 2006;55:301-5.

7. Migliori GB, De Laco G, Besozzi G, et al. First tuberculosis cases in Italy resisted to all tested drugs. Euro Surveill 2007;12:pii=3194.

8. Velayati AA, Masjedi MR, Farnia P, et al. Emergence of new forms of totally drug-resistant tuberculosis bacilli: super extensively drug-resistant tuberculosis or totally drug resistant strains in Iran. Chest 2009:136:420-5.

9. Bhargava A, Pinto L, Pai M. Mismanagement of tuberculosis in India: causes, consequences, and the way forward. Hypothesis 2011;9:e7.

10. Udwadia ZF, Pinto LM, Uplekar MW. Tuberculosis control by private practitioners in Mumbai, India: has anything changed in two decades? PLoS One 2010;5: e1203.

\section{Thorax alerts}

Sign up for our electronic table of contents alerts and you will never miss new issues of Thorax when published online. Stay ahead and up to date by visiting thorax.bmj.com. 